\title{
Housing and use of leverage in mental health treatment Stephanie LeMelle ${ }^{1}$ and John Monahan*2
}

Address: ${ }^{1}$ Columbia University/New York State Psychiatric Institute, 1051 Riverside Drive \#75, New York, New York 10804, USA and ${ }^{2}$ University of Virginia School of Law, 580 Massie Road, Charlottesville, Virginia 22903, USA

* Corresponding author

from WPA Thematic Conference. Coercive Treatment in Psychiatry: A Comprehensive Review

Dresden, Germany. 6-8 June 2007

Published: 19 December 2007

BMC Psychiatry 2007, 7(Suppl I):S27 doi:10.1 186/147I-244X-7-SI-S27

This abstract is available from: http://www.biomedcentral.com/I47I-244X/7/SI/S27

(c) 2007 LeMelle and Monahan; licensee BioMed Central Ltd.

\section{Background}

Low income housing in many parts of the United States, particularly in urban areas, is a scarce commodity. Because of the way metal health care is reimbursed in the US most people with persistent mental illness live on disability income (Social Security Income SSI). This puts people with mental illness below the poverty line and forces them to compete with other poor people for housing. It is also believed by some that people with mental illness need to be "housing ready" to live independently in the community. As a result, State mental health agencies often provide funding to community mental health providers to create different levels of supported housing for people with mental illnesses. Continued access to this type of housing is often conditioned on adherence to treatment. The intent of this study was to describe the use of housing as leverage with this population.

\section{Methods}

Interview data from 200 outpatients at five sites provided a description of the use of housing as leverage and of the specific types of housing most likely to be used as leverage.

\section{Results}

While experiencing housing as leverage was not associated with treatment satisfaction, it was significantly associated with feeling increased pressure to take prescribed medication and attend treatment sessions, feeling coerced into treatment, and less autonomy. Those individuals were also more likely to endorse the effectiveness of such leverage in causing treatment adherence.

\section{Conclusion}

Housing is often used as leverage to engage people in treatment for mental illness however, this study does not resolve the debate regarding the use of leverage to increase treatment adherence. It also raises the ethical issue of the use of housing as leverage. 